\title{
Hand Gesture Controlled Robot Arm
}

\author{
Elam Cheren.S, Madhubala.S, Pradeepa.C, Poovitha.M, Madumitha.B
}

\begin{abstract}
Robotic Arms are generally a programmable type of mechanical arm with functions similar to human arm which is either the sum of total mechanism or may be a complex robot part. These robotic arms are employed in assembly line of industries performing complex process like drilling, painting and painting etc. It is possible to fabricate gesture controlled Industrial robot arms. The robot is easily accessible and requires lesser controlling effects. In this work a glove attached to human hand is incorporated with flex sensors and transceiver. The flex sensor resistance can be varied by hand movement which is transferred to the axis of robot. The resistance of glove can make robot rotate either angular or in a linear motion about its axis. A transceiver circuit is employed for signal control which is capable of transmitting and receiving signal between human hand and robotic arm.The flex sensor senses and gives corresponding signals. The analog signal from the flex sensor given to Arduino, it will work according to the Arduino program. The signal is transmitted from Arduino to Zigbee for wireless communication. The driver circuit put together with transistor to control the relay. The relay output is connected directly to motor joined with the robot. With this arrangement arm can be used for pick and place application. The robotic arm delivers the programmed movement and the proposed model have widespread application for people working in hazardous areas.
\end{abstract}

Keywords: Zigbee, robotic arm, hand gesture

\section{INTRODUCTION}

In recent days, robots are used extensively in tasks to cut out human's effort particularly while performing the monotonous task. Generally robotics is classified into two, service and industrial robotics. A service robot is defined a robot which can act partially or fully autonomously and aids the service operation of humans and equipment effectively other than manufacturing process. They are currently employed in several areas of applications including military operations, dangerous environment, medical field and agriculture. Besides these robots are used in task difficult for a human to

Revised Manuscript Received on August 15, 2020.

* Correspondence Author

Elam Cheren.S*, Assistant Professor, Electrical and Electronics Engineering, Sri Krishna College of Engineering and Technology, Coimbatore, India. E-mail: elamcheren@gmail.com

Madhubala.S, UG Scholar, Electrical and Electronics Engineering, Sri Krishna College of Engineering and Technology, Coimbatore, India.

Pradeepa.C, UG Scholar, Electrical and Electronics Engineering, Sri Krishna College of Engineering and Technology, Coimbatore, India.

Poovitha.M, UG Scholar, Electrical and Electronics Engineering, Sri Krishna College of Engineering and Technology, Coimbatore, India.

Madumitha.B, UG Scholar, Electrical and Electronics Engineering, Sri Krishna College of Engineering and Technology, Coimbatore, India.

(C) The Authors. Published by Blue Eyes Intelligence Engineering and Sciences Publication (BEIESP). This is an open access article under the CC BY-NC-ND license (http://creativecommons.org/licenses/by-nc-nd/4.0/) perform like bomb defusing, handling explosive chemicals and monotonous pick and place work in factories. Hence a robot can be substituted instead human effort. A robotic arm is a programmed robot manipulator which can able to perform functions of a human arm. The manipulator are linked by joints which allows rotational motion or translational displacement. These manipulator links can create a kinematic chain, on the whole it is called as end effectors which is similar to the human hand. The end effectors are able to perform desired task such as welding, spinning etc., the arms can be controlled either autonomously or manually which can perform several operations with high accuracy. These arms are either fixed or mobile suitable for industrial and domestic applications.

\section{MATERIALS AND METHODS}

\section{A. Block Diagram}

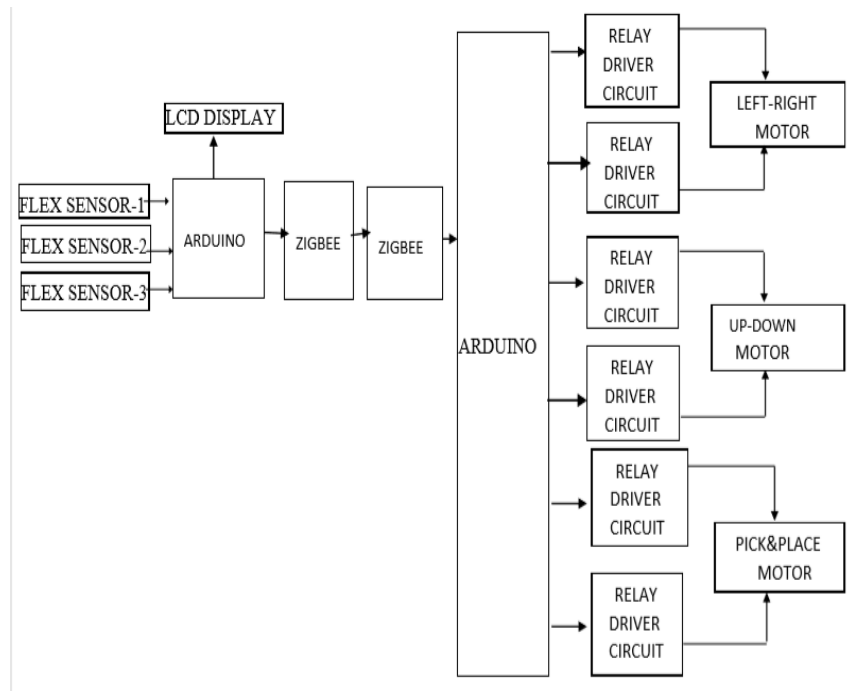

Fig.1 Block diagram for robot arm

The hardware mainly divided into two sections. They are

- Transmitter section

- Receiver section

\section{B. Flex Sensor}

A Flex sensor generally measures the deflection amount or bending. The output is taken from two wires. When bending action or force applied on the sensor there will be a change in resistance between two wires. An undeviated sensor without any acting force will have resistance around $10 \mathrm{~K}$ Ohms. A flex sensor constitutes thin flexible substrate within that carbon resistive elements are added.

Published By:

Blue Eyes Intelligence Engineering DOI: 10.35940/ijeat.E1019.089620

Journal Website: www.ijeat.org

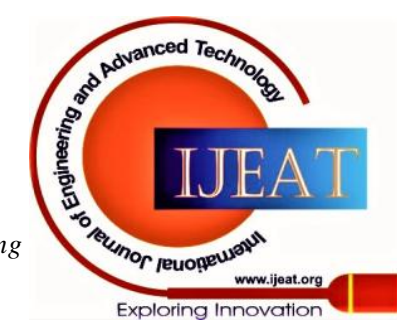




\section{Hand Gestured Controlled Robot Arm}

When substrate under bending process the sensor produces a output resistance proportional to radius of the bend. When a force is applied on the sensor or sensor is bent in either way, the resistance between these two wires varies proportionally to the amount of bending. Input of the flex sensor is $0-5 \mathrm{~V}$, there is change in resistance because of the bend made by movement and some voltage drop across the resistance, which is also the output voltage.

\section{Motor Drive}

It is a Current Amplifier whose operation is to convert a lower value control signal to a higher value signal which can able to drive a motor. It perform an interconnection between the control circuits and motor. Motor requires higher value of current and controller circuit requires low value signals. The L293D is a Motor Driver which can able to drive two DC motors simultaneously. The principle application of Motor Driver ICs are autonomous robotics and most of the processors operate at low voltages which needs small amount of current for operation but the motors requires a higher value voltages and current. The processor cannot able to supply motor and it is the principle necessity of motor driver IC. The block diagram is shown in figure and the Arduino will generate control signals. The signal generated by Arduino will be either HIGH $($ Vcc $=5 \mathrm{v})$ or LOW (zero).

BATTERY

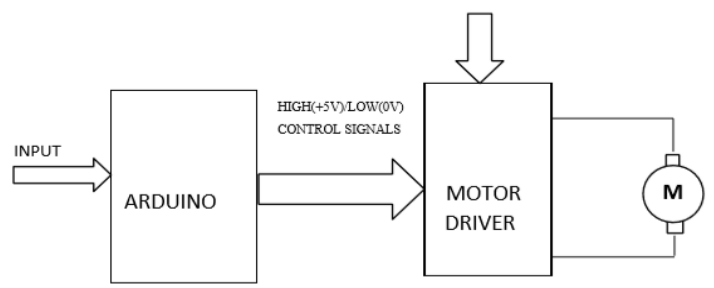

Fig.2 Block Diagram for Motor Drive

The L293D device is designed to generate current for driver circuit bidirectionally up to $600 \mathrm{~mA}$ and voltage ranges from $5 \mathrm{~V}$ to $36 \mathrm{~V}$. Bipolar driver for stepper motor or dual DC motor driver can be performed by adapter board.

\section{Relay Driver Circuit}

A relay driver IC is a switch which works electromagnetically used for circuit turn on and turn off by a low power signal or one signal controls several circuits. High end industrial application devices requires relays for effective operation. Relays made of two parts namely electromagnet and contact sets. The switching mechanism is carried by the electromagnet. The contacts are the most important part of the relay that affects the reliability. The good contact provides limited reduced contact wear and contact resistance. The contact material selection depends on factors like frequency, interrupting current magnitude, voltage of operation and nature of the interrupting current.

\section{E. Zigbee}

ZigBee is a high-level communication protocols based on an IEEE 802 standard for personal area networks using small, low-power digital radios. ZigBee devices are frequently employed in mesh network form to transmit long distance data, passing through intermediate devices to reach distant ones. So ZigBee networks are formed to ad-hoc without centralized control. ZigBee device can be performed with running the network which targeted at applications requires secure networking, low data rate and long battery life. The defined rate of Zigbee is $250 \mathrm{~kb} / \mathrm{s}$, mostly applicable for periodic or intermittent data or a single signal transmission from a sensor or input device. The technology defined by the ZigBee specification is simpler and cost effective than other WPANs, such as Bluetooth.

\section{F. DC gear motor}

A gear motor is designed to produce high torque and it is a merge of a motor and gearbox. The gear motors have different speed specifications like normal speed and the stall speed torque. The principle parameters of gear motors are speed, torque and efficiency. DC gear motors are assembled with gear which are attached to it. The speed of the motor is computed by shaft rotations per minute. The gear assembly enable higher torque and speed reduction. The speed reduction is possible by means of different combinations of gear assembly..

\section{HARDWARE IMPLEMENTATION}

The working principle is mainly based on the gesture that controls the robotic arm. The first part is getting data from the flex sensor. This sensor works on the bending strip principle which means whenever the strip is bent then its resistance will change. The resistance variation is due to the conducting ink present in the flex sensor. Whenever there is a supply to the flex sensor the conducting ink conducts and the resistor that is connected to the end of the sensor shows the voltage drop, now when the flex sensor is bent there is a breakage in the conducting path due to the conducting ink thus the resistance increases in the sensor thus there will a voltage drop in the form of analog signal that is converted into digital signal. Three flex sensors are employed for robotic arm movement. The flex sensor captures the movement of hand and transfers the analog signals to the Arduino board. These signals are passed to the arm through the ZigBee connected in both sides. The commands are transmitted as clock pulse to the arm through the ZigBee technology that supports the transfer of data without using wires. The ZigBee transfers the data to another ZigBee by using serial communication. The Arduino itself have $\mathrm{ADC}$ so it converts analog signal to the digital signal and transmits to the robotic arm. The digital signal is in the form of decimal value, which is displayed in the LCD display. Then Arduino sends the corresponding signal through the motor driver. The arm will move towards right, left, down, up directions and pick and place the objects depends on the command provided. The arm consists of three motors for left and right, up and down, pick and place respectively. The speed and torque of three motors differ from one another

\section{A. Working of flex sensor}

Flex sensor is made up of carbon surface on the plastic strip which measures the bending amount or deflection. It is a two terminal device whose resistance will change when the strip undergone deflection or bending.

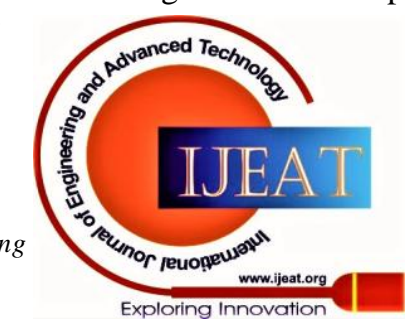


The resistance change is directly proportional to bending amount. It works on the principle of bending strip that means change in resistance due to bend can be measured by any controller. To interface with Arduino the sensor is powered by the board. One of the pin is connected to $+5 \mathrm{~V}$ of Arduino through $100 \mathrm{~K}$ resistor and another connected to ground pin of Arduino directly.

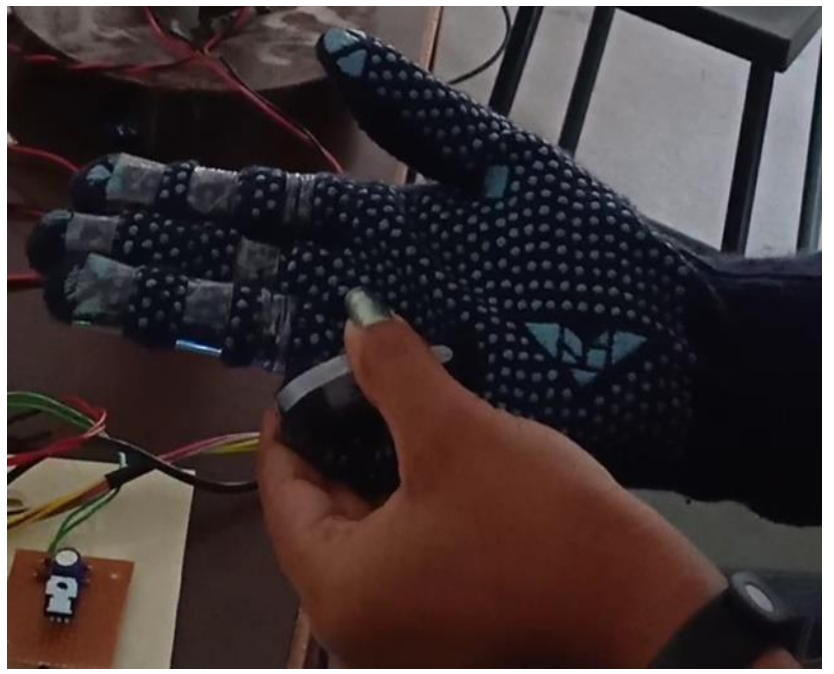

Fig.3 Working of Flex Sensor

\section{B. Working of Arduino}

Arduino is an open source platform and their boards are capable of reading input signals like a Twitter message, finger on a button which turns it into an output - by motor activation, light on a sensor turning on an LED. Simple connection of Arduino to computer with USB cable can able to get started. It is combination of physical programmable circuit board and a software that runs on our computer with which we can able fuse to the physical board. It has several features to communicating with computer, other Arduino or other microcontrollers. In our project it is used to control the robot arm in receiver section, in transmitter section it converts the analog signal from flex sensors to the digital signal by ADC which is inbuilt in Arduino, then transmits the data to zig-bee.

\section{Working of ZigBee}

ZigBee technology is a low power and low cost suitable for several embedded applications, wireless control and home automation. Mesh networking makes it highly reliable and used in extensive ranges. Data transmission ranges from 20 to $900 \mathrm{kB} / \mathrm{second}$. The network layer can able to support star, tree and generic mesh networks. Different network configurations like master to master or master to slave can be supported. Zigbee system consists of Zigbee coordinator, Router and end device and its network must consists of one coordinator which acts at its root..

\section{Working of DC gear motor}

A gear motors are mainly used in speed reduction application with cascaded gears can able to produce high torque. The primary objective is to reduce from high initial speed to lower value without affecting its mechanism negatively. The additional gear head of motor reduces the speed and increases the torque output. The necessary parameters of gear motors are speed, torque and efficiency.

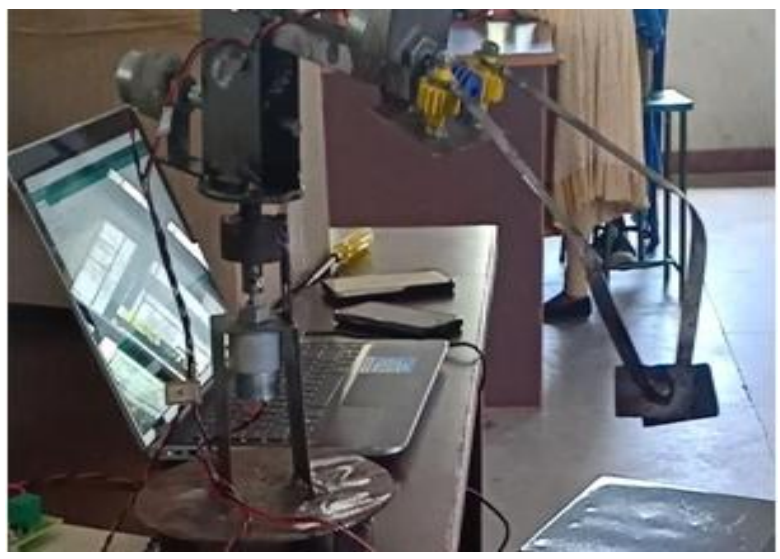

Fig.4 Working of Robot Arm

\section{E. Working of motor driver}

Motor driver concatenate the motor and control circuits. The microcontroller output are very low and it cannot able to run the motor. So iintermediate motor driver circuits are necessary to connect the controller to the motor. The purpose motor drivers is conversion of small current control signal into a large current signal which can drive a motor. L293D Motor Driver used in this work by which two DC motors can be drive simultaneously.

\section{F. Working of relay driver}

Relay driver are simple electromagnetic switches which can be used for turn off and turn process in a low voltage circuit in turn connected to high voltage supply. It allows low power circuit for signal control or $\mathrm{ON}$ and $\mathrm{OFF}$ of high current high current which is isolated electrically from control circuit. Based on the voltage rating of the relay it can able to turn on or turn off the control circuit based on the circuit operation. In this work relay driver are used to control the operation of DC gear motor which in turn controls the robotic arm.

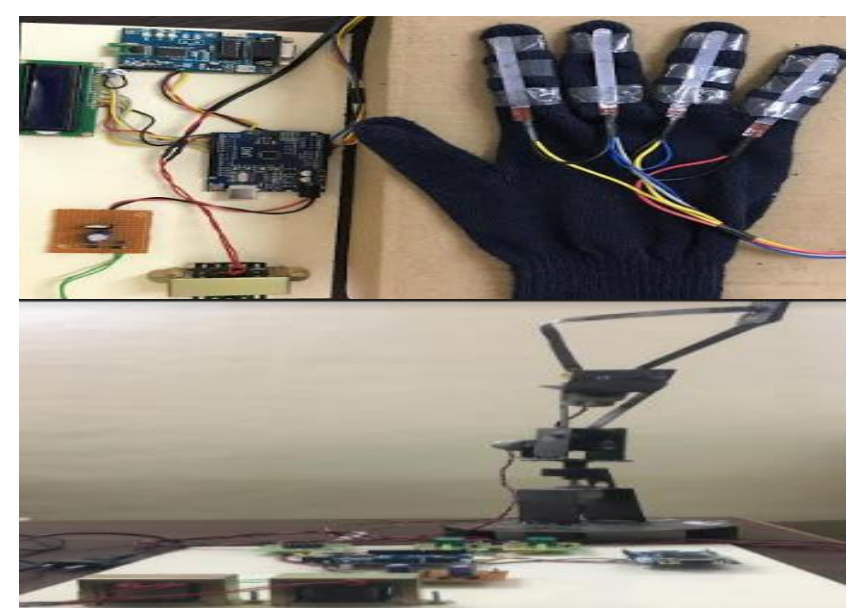

Fig.5 Prototype of Hand gesture controlled arm

\section{RESULT AND DISCUSSIONS}

The flex sensor working was tested by bending the sensor, if it works then the value will change in the LCD display according to the angle bend by the sensor, and if not then there is no change in value in LCD display. When the flex sensor F1 is bent with the values ranging F1 less than 250 and F1 is greater than 240 then the arm places the object.

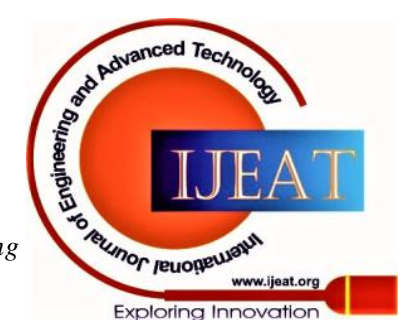




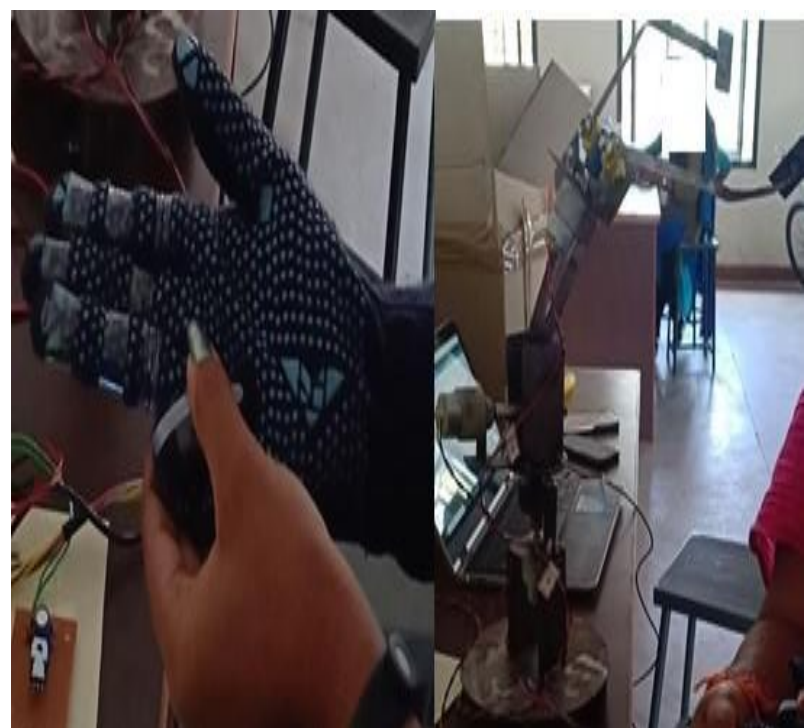

Fig.6 Flex Sensor F1 was bent, Arm Places the object

When the flex sensor F1 is bent, there is the drop in voltage and the value displays in LCD display. If the value in the LCD display less than 245, then the arm moves in the left direction.

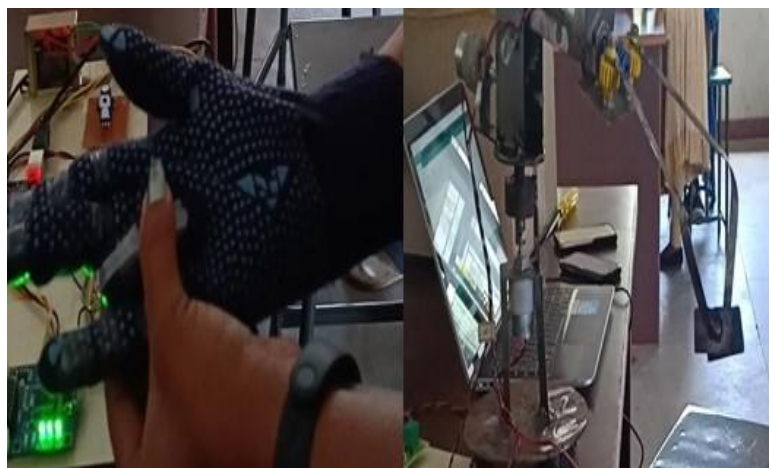

Fig.7 Flex Sensor F1 was bent, Arm moves towards left.

When the flex sensor F2 is bent with the values ranging F2 less than 250 the arm moves in the down direction.

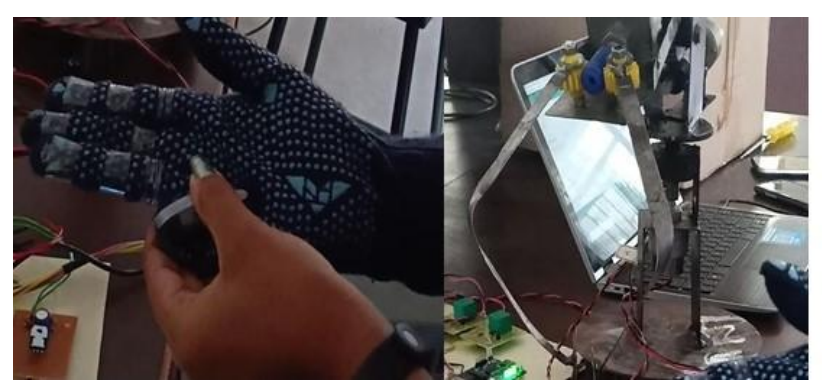

Fig.8 Flex Sensor F2 was bent, Arm move downwards

When the flex sensor F4 is bent with the values ranging F4 less than 252 and F4 is greater than 245 the arm moves in the upward direction.

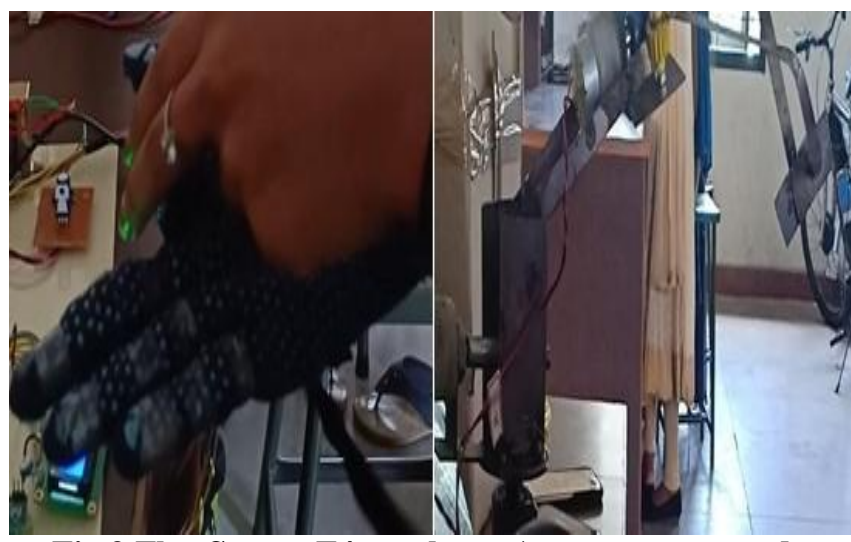

Fig.9 Flex Sensor F4 was bent, Arm move upwards.

When the flex sensor F4 is bent with the values ranging F4 less than 238 the arm picks the object.

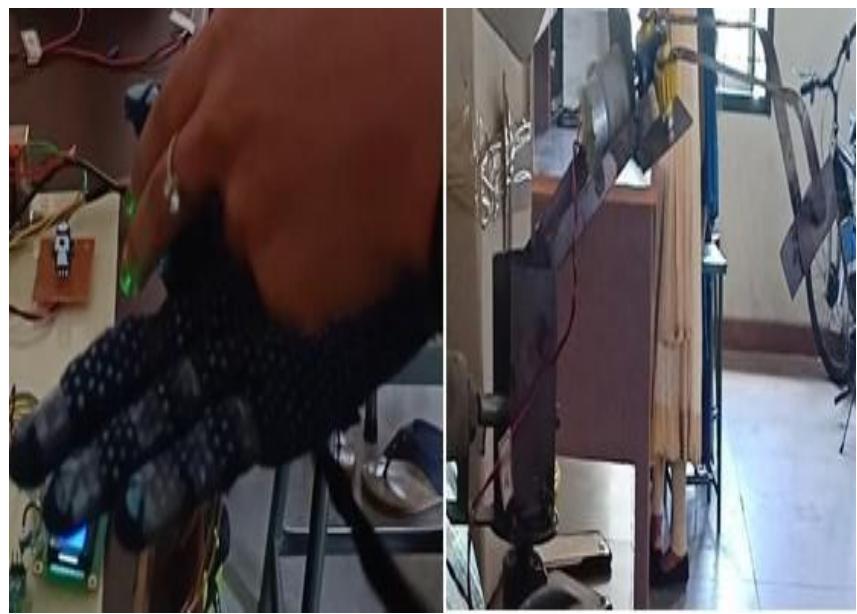

Fig.10 Flex Sensor F4 was bent, Arm picks the object.

When the flex sensor F1 and F4 are bent with the values ranging $\mathrm{F} 1$ less than 245 and $\mathrm{F} 4$ less than 240 the arm moves in the right direction.

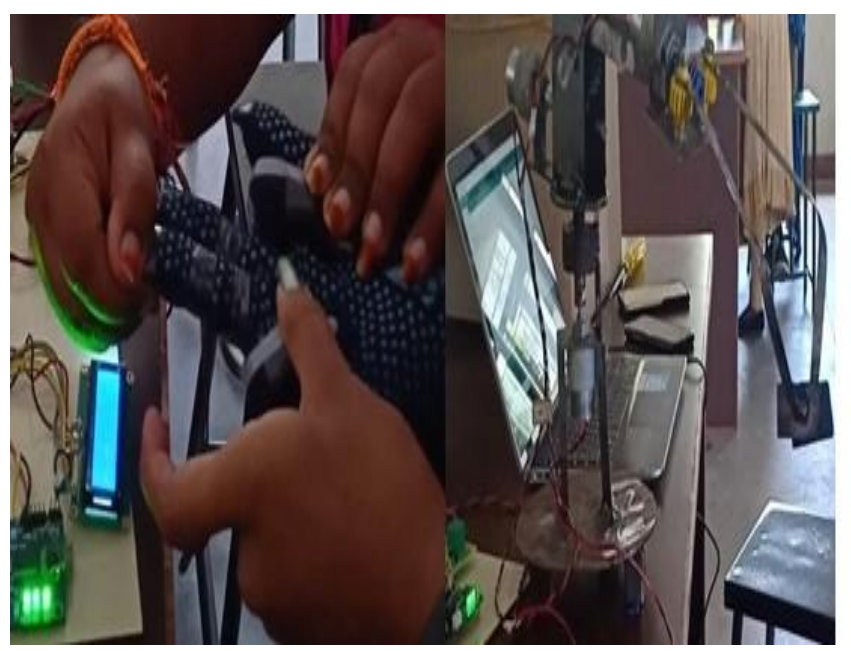

Fig.11 Flex Sensor F4 and F4 was bent, Arm moves right

\section{CONCLUSION}

The outcome of this work is to control a robotic arm using flex sensors pinned with a hand glove. The sensors are employed for remote control that will enable forward, backward, left and right control movements and pick and drop depends on the hand movements.

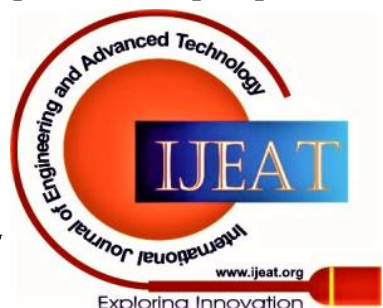


The hardware setup was designed which results in the robotic arm formation. The software section enables movements processing wherein the hand gestures were analyzed to extract the actual direction. The identified direction was transferred to the robotic arm through Zigbee. The command for the robotic arm is to direct specifically in the surroundings which is enabled by hand gestures technique adopted by the user. The use of external hardware support for gesture input not necessary like specified existing system. This working model enables user to control a robotic arm from his software station

\section{REFERENCES}

1. Mohd Ashiq Kamaril Yusoffa, Reza Ezuan Saminb, Babul Salam Kader Ibrahimc, "Wireles Mobile Robotic Arm", International Symposium on Robotics and Intelligent Sensors , July 2018

2. Wan Muhamad Hanif Wan Kadir, Reza Ezuan Samin, Babul Salam Kader Ibrahim, "Internal Controller Robotic Arm". International Symposium on Robotics and Intelligent Sensors , March 2016

3. Paul Smith, "Programming with AVRDUDE", http://www.ladyada.net/learn/avr/ avrdude.html/, April 2017.

4. Khajone, S. A., Mohod, S.W., \& Harne, V. M.,(2015), "Implementation of wireless Gesture Controlled Robotic Arm", International Journal of Innovative research in computer and Communication Engineering.

5. Bhuyun,A.I.,\&Mallick,T.C.,(2018)"Gyro-Accelerometer Based Control of a Robotic Arm Using AVR Microcontroller",9th IEEE International firum on Strategic Technology(IFOST),2018.

6. Aggarwal,L.,Gaur,V., \& Verma,P.,(2017)"Design and Implementation of a Wireless Gesture Controlled Robotic Arm with Vision",International Journal of Computer Applications.

7. Brahmani ,K.,Roy,K,S., \& Ali, M.,(2018)"Arm 7 Based Robotic Arm Control by Electronics Gesture Recognition Unit Using MEMS", International Journal of Engineering Trends and Technology.

\section{AUTHORS PROFILE}

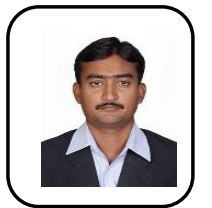

Elam Cheren S Currently working as Assistant Professor in the Department of Electrical and Electronics Engineering, Sri Krishna College of Engineering and Technology, Coimbatore. His research area includes Power converters, Renewable Energy Systems and Industrial Automation.

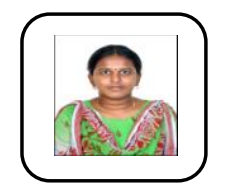

Madhubala S Completed B.E in Department of Electrical and Electronics Engineering, Sri Krishna College of Engineering and Technology, Coimbatore. Her research area includes Electrical Machines and Power Electronics.

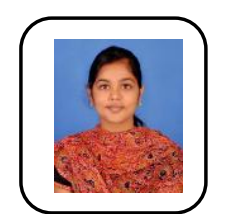

Pradeepa C Completed B.E in Department of Electrical and Electronics Engineering, Sri Krishna College of Engineering and Technology, Coimbatore. Her research area includes Robotics and Microcontrollers.

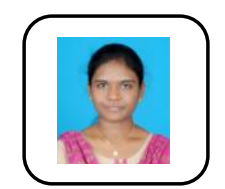

Poovitha M Completed B.E in Department of Electrical and Electronics Engineering, Sri Krishna College of Engineering and Technology, Coimbatore. Her research area includes Robotics and Neural Networks.

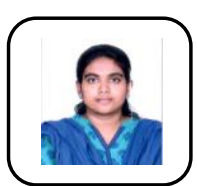

Madumitha B Completed B.E in Department of Electrical and Electronics Engineering, Sri Krishna College of Engineering and Technology, Coimbatore. Her research area includes Robotics and Neural Networks. 